\title{
Risk factors for cancer development in type 2 diabetes: A retrospective case-control study
}

\author{
Mariusz Dąbrowski ${ }^{1,6^{*}}$, Elektra Szymańska-Garbacz², Zofia Miszczyszyn ${ }^{3}$, Tadeusz Dereziński ${ }^{4}$ \\ and Leszek Czupryniak ${ }^{5}$
}

\begin{abstract}
Background: The risk of several types of cancer is increased in type 2 diabetes mellitus. The earliest possible diagnosis of cancer - difficult within regular outpatient diabetes care - is of utmost importance for patients' survival. The aim of this multicenter, retrospective (years 1998-2015), case-control study was to identify risk factors associated with malignancy in subjects with diabetes treated in a typical outpatient setting.

Methods: In the databases of 3 diabetic and 1 primary care clinics 203 patients (115 women) with type 2 diabetes mellitus who developed malignancy while treated for diabetes were identified. The control group consisted of 203 strictly age- and gender matched subjects with type 2 diabetes without cancer. Factors associated with diabetes: disease duration, antidiabetic medications use and metabolic control of diabetes were analyzed. Also other variables: BMI (body mass index), smoking habits, place of residence and comorbidities were included into analysis.

Results: The most prevalent malignancies in men and women together were breast cancer (20.7 \%) and colorectal cancer (16.3\%). $\mathrm{HbA}_{1 \mathrm{c}}$ (hemoglobin $\mathrm{A}_{1 \mathrm{c}}$ ) level $\geq 8.5 \%$, obesity and insulin treatment in dose-dependent and timevarying manner demonstrated significant association with increased risk of malignancy, while metformin use was associated with a lower risk of cancer. Diabetes duration, comorbidities, smoking habits, place of residence and aspirin use did not show significant association with risk of malignancy.

Conclusions: In the outpatient setting the obese patients with poorly controlled insulin treated type 2 diabetes mellitus should be rigorously assessed towards malignancies, particularly breast cancer in women and colorectal cancer in men.
\end{abstract}

Keywords: Cancer, Diabetes, Insulin, Metformin, Obesity,

\section{Background}

Association between diabetes and cancer has been known for decades [1, 2]. Type 2 diabetes mellitus (T2DM) can be considered as a risk factor of several types of malignant neoplasms [3-11]. In cancer development both genetic and environmental factors play an important role [12, 13]. Among possible biological mechanisms directly linking diabetes and cancer,

* Correspondence: mariusz.dabrowski58@gmail.com; madab@esculap.p ${ }^{1}$ Faculty of Medicine, Institute of Nursing and Health Sciences, University of Rzeszow, Al. Mjr. W. Kopisto 2a, 35-310 Rzeszów, Poland

${ }^{6} \mathrm{NZOZ}$ "Beta-Med", Plac Wolności 17, 35-073 Rzeszow, Poland

Full list of author information is available at the end of the article hyperinsulinemia, hyperglycemia and inflammation are pointed out [14-16].

It is widely assumed that glucose-lowering therapy may influence malignancy risk in diabetic subjects. Metformin is considered to play a protective role in cancer development and outcomes [17], whilst exogenous insulin use seems to be associated with an elevated cancer risk [18]. Oncogenic effects of newer antidiabetic medications is still a matter of uncertainty [19]. Since the earliest possible diagnosis of cancer is of utmost importance for patients' survival, identification of clinically relevant risk factors of cancer among diabetic patients may be helpful in identifying subjects at greater risk of malignancy. 
The aim of this multicenter, retrospective, case-control study was to identify risk factors associated with malignancy in subjects with diabetes treated in a typical outpatient setting.

\section{Methods}

The study was approved by the institutional Bioethics Committee at the University of Rzeszow and by the all appropriate administrative bodies. The study was carried out in accordance with ethical standards laid down in Polish regulations and in an appropriate version of the Declaration of Helsinki (as revised in Brazil 2013).

After Bioethics Committee approval, we performed retrospective analysis of existing individual patients' records in the databases of 3 diabetic and 1 primary care clinics. Inclusion criteria for the 'case' group included: cancer diagnosed after diagnosis of type 2 diabetes, at least one $\mathrm{HbA}_{1 \mathrm{c}}$ measurement before or at the time of cancer diagnosis, date of diabetes diagnosis, diabetes treatment, BMI and history of comorbidities available. We identified 203 patients (115 women) with T2DM eligible for analysis. Data analysis covered the period from January 1998 (the first eligible patient with diagnosed cancer) to 30 April 2015. The mean age of diabetic patients at the time of cancer diagnosis was $67.1 \pm 9.7$ years, and 141 persons were aged $\geq 65$ years. The control group consisted of 203 strictly age- and gender matched subjects with T2DM without cancer. Patients were selected from the same databases in the case-control manner, with the 1:1 ratio. For each 'case' patient, an eligible 'control' subject with the same gender, and with the nearest possible date of birth was chosen, and any given pair was recruited always at one center to avoid impact of different treatment algorithms used in different clinics. Individuals who died within the analyzed time period but before the moment of data collection were also included into the analysis if their data were available. Data for patients with malignancy were taken from the period preceding cancer diagnosis (index time). Data for the 'control' subjects were assessed from the same index time, i.e., if the 'case' patient had cancer diagnosed in April 2009, the data for his/her comparator were taken from the same period.

In both groups metabolic control of diabetes (mean $\mathrm{HbA}_{1 \mathrm{c}}$ from the preceding up to 3 years before index time, if available), diabetes duration, antidiabetic medications (also from the preceding up to 3 years, and each drug was classified as "used" if it was taken for at least 6 months), mean insulin dose from the preceding 6 months, and duration of insulin treatment up to the moment of cancer diagnosis were analyzed. Also place of residence (rural, small cities or urban), smoking habits (current, former or never smoker), presence of comorbidities (hypertension, hyperlipidemia and cardiovascular disease), BMI and use of aspirin were also included into the analysis. All included patients were of Caucasian ethnicity. Detailed characteristics of both groups is presented in the Table 1.

Current place of residence was taken into analysis with the exception of patients, who moved in the last year. In such cases a previous place of residence was taken into account. Patients were considered as a current, former or never smokers according to definition stated by Centers for Disease Control and Prevention [20]. Hypertension was considered if blood pressure values were $\geq 140 \mathrm{mmHg}$ for systolic, and/or $\geq 90 \mathrm{mmHg}$ for diastolic blood pressure, or if antihypertensive medications were used. Hyperlipidemia was recognized if LDL-cholesterol level was $\geq 2.6 \mathrm{mmol} / \mathrm{L}(100 \mathrm{mg} / \mathrm{dl})$ and/or triglycerides concentration was $\geq 1.7 \mathrm{mmol} / \mathrm{L}(150 \mathrm{mg} / \mathrm{dl})$, or hypolipemic drugs were used. Cardiovascular disease was confirmed if the patient had a history of non-fatal myocardial infarction, hospitalization for acute coronary syndrome, non-fatal stroke, revascularization or amputation.

Statistical analysis of the data was performed using SigmaPlot for Windows version 12.5 (Systat Software Inc., San Jose, CA, USA). The analysis was performed in 2 stages. In the first stage comparison of the two groups was made. The continuous data were analyzed using an unpaired two-tailed Student's $t$-test or by a MannWhitney rank sum test where appropriate. The categorical data were compared using $X^{2}$ test. In the second stage patients were divided into subgroups according to BMI $\left(<25.0,25.0-29.9,30.0-34.9\right.$ and $\left.\geq 35.0 \mathrm{~kg} / \mathrm{m}^{2}\right)$, diabetes duration $(<5.0,5.0-9.9,10.0-14.9$ and $\geq 15.0$ years), insulin dose (no insulin, $<0.50$ and $\geq 0.50 \mathrm{IU} / \mathrm{kg}$ ) and duration of insulin treatment (no insulin, <5.0, 5.0-9.9 and $\geq 10.0$ years). For the assessment of the effect of treatment or analyzed risk factors on cancer occurrence OR (odds ratios) and $95 \% \mathrm{CI}$ (confidence intervals) were calculated in univariate and in multiple logistic regression models. A $P$ value $<0.05$ was considered statistically significant.

\section{Results}

The most prevalent malignancies in the whole group were: breast, colorectal and uterine cancers (Fig. 1). Among women the most prevalent cancer sites were: breast (36.5\%), uterus (13.9\%), colon with rectum (9.6\%), lung (5.2\%) and stomach $(4,4 \%)$, while in men there were: colon with rectum $(25.0 \%)$, prostate (13.6\%), kidney (10.2\%), lung (10.2\%) and pancreas (9.1\%).

\section{Metabolic control}

Mean $\mathrm{HbA}_{1 \mathrm{c}}$ level was not significantly different between the case and control groups. However, a sharp 
Table 1 Characteristics of the case and control groups

\begin{tabular}{|c|c|c|c|}
\hline Parameter & Malignancy & No malignancy & $P$ value* \\
\hline Age at index time (years) (mean \pm SD) & $67.1 \pm 9.7$ & $67.1 \pm 9.7$ & - \\
\hline$<65$ years $(n)$ & $62(30.5 \%)$ & $62(30.5 \%)$ & \\
\hline$\geq 65$ years $(n)$ & $141(69.5 \%)$ & $141(69.5 \%)$ & \\
\hline Gender & & & - \\
\hline male $(n)$ & $88(43.3 \%)$ & $88(43.3 \%)$ & \\
\hline female $(n)$ & $115(56.7 \%)$ & $115(56.7 \%)$ & \\
\hline Place of residence & & & 0.264 \\
\hline rural (n) & 38 (18.7 \%) & $44(21.7 \%)$ & \\
\hline cities <50,000 inhabitants (n) & $27(13.3 \%)$ & $36(17.7 \%)$ & \\
\hline cities > 50,000 inhabitants ( $\mathrm{n}$ ) & $138(68.0 \%)$ & $123(60.6 \%)$ & \\
\hline Smoking habits & & & 0.838 \\
\hline never smokers (n) & 115 (56.7 \%) & $117(57.6 \%)$ & \\
\hline former smokers (n) & $54(26.6 \%)$ & 57 (28.1 \%) & \\
\hline current smokers (n) & $33(16.3 \%)$ & $29(14.3 \%)$ & \\
\hline unknown status (n) & $1(0.5 \%)$ & - & \\
\hline BMI $\left(\mathrm{kg} / \mathrm{m}^{2}\right)($ mean $\pm \mathrm{SD})$ & $30.8 \pm 5.3$ & $30.1 \pm 4.7$ & 0.103 \\
\hline \multicolumn{4}{|l|}{ Comorbidities } \\
\hline cardiovascular disease $(n)$ & $50(24.6 \%)$ & $58(28.6 \%)$ & 0.369 \\
\hline hypertension (n) & 177 (87.2 \%) & $179(88.2 \%)$ & 0.763 \\
\hline hyperlipidemia (n) & $153(75.4 \%)$ & $159(78.3 \%)$ & 0.480 \\
\hline Diabetes duration (years) (mean \pm SD) & $10.7 \pm 7.4$ & $10.3 \pm 8.1$ & 0.262 \\
\hline $\mathrm{HbA}_{1 \mathrm{c}}(\%)($ mean $\pm \mathrm{SD})$ & $7.39 \pm 1.21 \%$ & $7.30 \pm 1.06 \%$ & 0.755 \\
\hline \multicolumn{4}{|l|}{ Antidiabetic medications } \\
\hline metformin (n) & $126(62.1 \%)$ & $167(82.3 \%)$ & $<0.001$ \\
\hline sulfonylurea (n) & $83(40.9 \%)$ & $101(49.8 \%)$ & 0.090 \\
\hline acarbose (n) & $18(8.9 \%)$ & $14(6.9 \%)$ & 0.581 \\
\hline DPP-4 inhibitor (n) & $11(5.4 \%)$ & $6(3.0 \%)$ & 0.322 \\
\hline insulin (n) & $110(54.2 \%)$ & 81 (39.9\%) & 0.005 \\
\hline insulin dose (IU/kg/24 h) (mean \pm SD) & $0.59 \pm 0.31$ & $0.53 \pm 0.24$ & 0.407 \\
\hline insulin duration (years) (mean $\pm S D$ ) & $6.2 \pm 5.6$ & $6.5 \pm 4.9$ & 0.529 \\
\hline Aspirin use (n) & $102(52.6 \%)$ & $102(52.8 \%)$ & 0.957 \\
\hline unknown status & 9 & 10 & \\
\hline
\end{tabular}

NS non significant

* between malignancy and non-malignancy groups

increase of cancer risk was observed among patients with $\mathrm{HbA}_{1 \mathrm{c}}$ level $\geq 8.5 \%$ (Fig. 2), and these patients had significantly elevated risk of malignancy compared with the remaining subjects, OR $1.802(1.030-3.153), p=$ 0.037 .

\section{Diabetes duration}

Duration of diabetes did not differ significantly between the two groups. Also when patients were divided into four groups according to diabetes duration, no significant differences were found (Fig. 2).

\section{Diabetes treatment}

Significantly fewer patients in the case group were treated with metformin compared to the control group (Table 1). This difference was significant both in the univariate analysis and after adjustment for BMI, diabetes duration, metabolic control, other antidiabetic medications use and all other variables. Insulin use both in the crude analysis and after adjustment for BMI, diabetes duration and metabolic control was associated with significantly elevated risk of cancer occurrence. After adjustment for other variables in the multiple logistic regression analysis it was attenuated to non-significant 


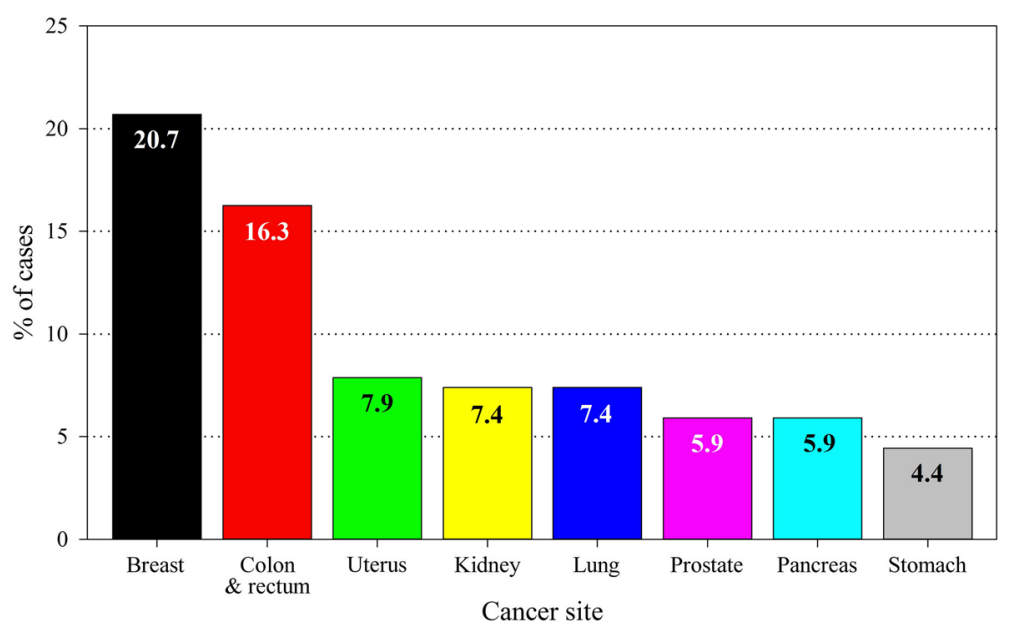

Fig. 1 Cancer sites with over $4 \%$ prevalence in the studied population

level. No significant associations were found for other antidiabetic medications, with the exception of DPP-4 (dipeptidyl-peptidase -4) inhibitors, which after adjustment to all analyzed covariates appeared to be associated with elevated risk of cancer occurrence (Fig. 2 and Table 2). However, only 17 patients (4.2\%) among the whole group of 406 subjects were treated with these medications.
Although mean insulin dose and mean duration of insulin use were not significantly different between the case and control groups, insulin treatment has shown association with the risk of malignancy occurrence in a dose-dependent and time-varying manner $\left(\mathrm{P}_{\text {trend }} 0.015\right.$ and 0.027 respectively). The risk of cancer was increasing together with increasing insulin dose and the highest

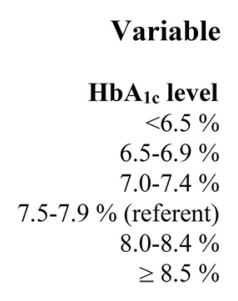

Diabetes duration (years) $<5.0$ (referent)

$5.0-9.9$

$10.0-14.9$

$\geq 15.0$

Antidiabetic medications

Metformin

Sulfonylureas

Acarbose

DPP-4 inhibitors

Insulin

Insulin dose (IU/kg)

no insulin (referent)

$<0.50$

$\geq 0.50$

Insulin duration (years)

no insulin (referent)

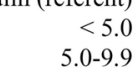

$5.0-9.9$

$\geq 10.0$

0.1

\section{OR $(95 \%$ CI) \\ P value}

$1.380(0.710-2.681) \quad 0.433$

$1.389(0.701-2.752) \quad 0.441$

$1.155(0.579-2.302) \quad 0.815$

1.000

$1.003(0.455-2.213) \quad 0.846$

$\begin{array}{ll}2.181(1.047-4.542) & \mathbf{0 . 0 3 6}\end{array}$

1.000

$1.081(0.629-1.860) \quad 0.885$

$1.677(0.949-2.964) \quad 0.101$

$1.214(0.681-2.164) \quad 0.609$

$353(0.223-0.558) \quad<0.001$

$\begin{array}{ll}0.699(0.472-1.034) & 0.090\end{array}$

$1.314(0.635-2.718) \quad 0.581$

$1.881(0.682-5.187) \quad 0.322$

$1.781(1.202-2.641) \quad 0.005$

1.000

$1.713(1.027-2.855) \quad 0.038$

$1.837(1.150-2.933) \quad 0.015$

.000

$1.895(1.145-3.135) \quad 0.017$

$1.942(1.093-3.449) \quad 0.032$

$1.377(0.705-2.690) \quad 0.442$

Fig. 2 Diabetes-related risk factors of cancer occurrence 
Table 2 Adjusted risk of malignancy associated with antidiabetic medications, use vs. non-use

\begin{tabular}{|c|c|c|c|c|c|c|}
\hline Antidiabetic medication & $\begin{array}{l}\mathrm{OR}^{\mathrm{a}} \\
(95 \% \mathrm{Cl})\end{array}$ & $P$ value & $\begin{array}{l}\mathrm{OR}^{\mathrm{b}} \\
(95 \% \mathrm{Cl})\end{array}$ & $P$ value & $\begin{array}{l}\mathrm{OR}^{\mathrm{C}} \\
(95 \% \mathrm{Cl})\end{array}$ & $P$ value \\
\hline Metformin & $\begin{array}{l}0.294 \\
(0.182-0.478)\end{array}$ & $<0.001$ & $\begin{array}{l}0.318 \\
(0.193-0.523)\end{array}$ & $<0.001$ & $\begin{array}{l}0.310 \\
(0.183-0.525)\end{array}$ & $<0.001$ \\
\hline Sulfonylurea & $\begin{array}{l}0.735 \\
(0.493-1.094)\end{array}$ & 0.129 & $\begin{array}{l}0.859 \\
(0.547-1.349)\end{array}$ & 0.508 & $\begin{array}{l}0.906 \\
(0.563-1.456)\end{array}$ & 0.683 \\
\hline Acarbose & $\begin{array}{l}1.333 \\
(0.640-2.776)\end{array}$ & 0.443 & $\begin{array}{l}1.372 \\
(0.635-2.967)\end{array}$ & 0.421 & $\begin{array}{l}1.245 \\
(0.564-2.747)\end{array}$ & 0.587 \\
\hline DPP-4 inhibitors & $\begin{array}{l}1.954 \\
(0.698-5.468)\end{array}$ & 0.202 & $\begin{array}{l}2.809 \\
(0.947-8.331)\end{array}$ & 0.063 & $\begin{array}{l}3.468 \\
(1.082-11.112)\end{array}$ & 0.036 \\
\hline Insulin & $\begin{array}{l}1.964 \\
(1.227-3.144)\end{array}$ & 0.005 & $\begin{array}{l}1.509 \\
(0.879-2.588)\end{array}$ & 0.135 & $\begin{array}{l}1.735 \\
(0.986-3.053)\end{array}$ & 0.056 \\
\hline
\end{tabular}

adjusted for BMI, diabetes duration and metabolic control

${ }^{b}$ adjusted for $\mathrm{BMI}$, diabetes duration, metabolic control and antidiabetic medications use

c adjusted for BMI, diabetes duration, metabolic control, antidiabetic medications use, smoking history, place of residence, presence of comorbidities and aspirin use

Data presented in bold are statistically significant

risk was revealed in patients using insulin at a dose $\geq 0.50 \mathrm{IU} / \mathrm{kg}$. Interestingly, the highest risk was observed in the first 10 years of insulin therapy and it was decreasing thereafter (Fig. 2).

\section{BMI}

Mean BMI was not significantly different between the case and control groups. However, risk of malignancy was increasing with the increasing BMI (Fig. 3). Obesity (BMI $\geq 30 \mathrm{~kg} / \mathrm{m}^{2}$ ) was associated with significantly elevated risk of malignancy, OR 1.608 (95\% CI 1.087-2.380), $\mathrm{P}=0.022$ compared to patients with lower BMI. After adjustment for duration of diabetes, its metabolic control and antidiabetic medications use this relationship become even stronger, OR 2.013 (1.310-3.092), $P=0.001$.

\section{Other variables}

None of the other analyzed variables had significant effect on risk of malignancy among study participants (Fig. 3). Only among patients with lung cancer smoking (ever vs. never) was associated with significantly elevated risk of malignancy, OR 11.000 (1.998-60.572), $\mathrm{P}=0.003$. No association was found for other site-specific cancers.

\section{Discussion}

Although the link between diabetes and malignant neoplasms is well known and many site-specific cancers are

\begin{tabular}{|c|c|c|c|}
\hline Variable & & OR $(95 \%$ CI $)$ & $P$ value \\
\hline \multicolumn{4}{|l|}{ BMI $\left(\mathbf{k g} / \mathbf{m}^{2}\right)$} \\
\hline$<25.0$ & $-\infty$ & $1.141(0.587-2.218)$ & 0.826 \\
\hline 25.0-29.9 (referent) & 0 & 1.000 & \\
\hline $30.0-34.9$ & $\longrightarrow$ & $1.540(0.969-2.447)$ & 0.087 \\
\hline$>35.0$ & $\longmapsto$ & $1.910(1.076-3.390)$ & 0.038 \\
\hline \multicolumn{4}{|l|}{ Smoking status } \\
\hline Never smokers (referent) & 0 & 1.000 & \\
\hline Former smokers & $\longmapsto 0-1$ & $0.964(0.613-1.515)$ & 0.965 \\
\hline Current smokers & $\longmapsto-1$ & $1.158(0.660-2.030)$ & 0.712 \\
\hline \multicolumn{4}{|l|}{ Place of residence } \\
\hline Rural (referent) & 0 & 1.000 & \\
\hline Small cities & -0 & $0.868(0.448-1.682)$ & 0.803 \\
\hline Urban & $\longmapsto-1$ & $1.299(0.790-2.136)$ & 0.365 \\
\hline \multicolumn{4}{|l|}{ Comorbidities } \\
\hline Hypertension & $\longmapsto \circ$ & $0.913(0.505-1.651)$ & 0.880 \\
\hline Hyperlipidemia & $\longmapsto 0-1$ & $0.847(0.534-1.344)$ & 0.556 \\
\hline CVD & $\longmapsto+-1$ & $0.817(0.526-1.270)$ & 0.432 \\
\hline & & 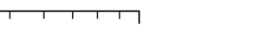 & \\
\hline 0,1 & 1 & 10 & \\
\hline
\end{tabular}


more prevalent in diabetic patients [3-11], the exact risk factors of cancer in diabetic population have not been fully determined. Also in our study prevalence of breast, colorectal, uterine, kidney, pancreatic and gastric cancers among diabetic patients was higher, while proportion of patients with prostatic and lung cancers was lower than observed in the general Polish population [21], which is in line with majority of other observations [4-7, 22].

Our retrospective, multicenter, case-control study revealed that the following diabetes-related factors may be associated with cancer occurrence: poor metabolic control, obesity and antidiabetic medications use. Importantly, age and gender were not included into risk analysis, because the patients were strictly matched according to them.

Data regarding association between $\mathrm{HbA}_{1 \mathrm{c}}$ level and risk of malignancy are divergent. Some studies showed continuous relationship between increasing $\mathrm{HbA}_{1 \mathrm{c}}$ level and cancer risk [23-25], others found non-linear association $[26,27]$ (the second one only among women), or elevated risk of malignancy above the specified $\mathrm{HbA}_{1 \mathrm{c}}$ threshold of $7.5 \%$ (colorectal cancer) [28]. In the study by Miao Jonasson et al. no relationship between $\mathrm{HbA}_{1 \mathrm{c}}$ level and cancer was found [29]. In the recent meta-analysis significant association between chronic hyperglycemia and elevated risk of several types of malignancies with the exception of prostate cancer was demonstrated [30]. We took to the analysis the mean $\mathrm{HbA}_{1 \mathrm{c}}$ level from a longer period of time preceding cancer diagnosis considering it as better reflecting the overall exposure to glucose than single measurement. In our study risk of malignancy was rising rapidly at the $\mathrm{HbA}_{1 \mathrm{c}}$ level equal or above $8.5 \%$. de Beer and Liebenberg found similar $\mathrm{HbA}_{1 \mathrm{c}}$ threshold for the risk of colorectal and breast cancers [30]. In our study these cancers were $37 \%$ of all malignancies, which partly explains our findings.

Some of the studies cited above were performed in diabetic populations $[23-25,29]$, while other were conducted in both non-diabetic and diabetic subjects [26-28]. Although deleterious effect of glucose and elevated cancer risk as a function of $\mathrm{HbA}_{1 \mathrm{c}}$ may be seen also in a higher versus lower values within a normal range, it can be more pronounced at high glucose concentrations. The higher threshold found in our study can be explained by the fact that prolonged hyperglycemia leads to formation of ROS (reactive oxygen species) and to accumulation of AGEs (advanced glycation end products). AGEs stimulate their specific receptor RAGE (receptor for AGE) which leads to increased inflammation through the activation of the nuclear transcription factor NF- $\mathrm{KB}$ and formation of ROS in the cells, which have mutagenic effect and cause DNA damage. This pathway is considered to play an important role in both inflammation and carcinogenesis [31, 32]. Chronic hyperglycemia activates these biological processes and thus a higher $\mathrm{HbA}_{1 \mathrm{c}}$ value may reflect higher cancer risk in poorly controlled diabetes. In addition, glucose serves is a primary energy source for cancer cells, and higher glucose concentrations may accelerate cancer growth [33, 34].

Data regarding effect of diabetes duration on cancer risk are scarce. Johnson et al. and the Danish registry study documented highest cancer risk occurring immediately after diabetes diagnosis [35, 36]. However, Li et al. demonstrated opposite results, with the lowest risk of malignancy in the first 5 years from the onset of diabetes, and the highest cancer risk among patients with diabetes lasting over 15 years [37]. In our study there was a clear tendency towards lowest cancer risk in the first years, and the highest risk between 10 and 15 years after diagnosis of diabetes. The increasing risk of cancer incidence with duration of diabetes can be explained by cumulative effect of hyperglycemia, use of insulin, and weight gain developing in the course of the disease. In addition, increasing age itself is strongly associated with increasing cancer risk both in diabetic and non-diabetic population $[21,38]$.

Impact of antidiabetic medications on cancer risk has been widely discussed in recent years. As a progressive disease type 2 diabetes requires intensification of treatment over time, from lifestyle modification through oral therapy in different regimens, to insulin treatment. Thus, a clear impact of antidiabetic medications on cancer risk is difficult to determine.

Our study demonstrated highly significant reduction of cancer risk among metformin users, which is in line with many $[17,19,39,40]$ but not all [41] studies. The mechanisms of the anti-cancer effect of metformin include inhibition of cancer cells growth through stimulation of AMPK (AMP-activated protein kinase) and its regulator LKB1 (liver kinase B1), which is known to act as a tumor suppressor protein. In addition, metformin also directly inhibits mTOR (mammalian target of rapamycin) pathway [42] and may have a role of immunomodulator [43].

Sulfonylurea (SU) use in our study did not show relationship with cancer risk. Data from other observations are divergent. Soranna et al. demonstrated neutral effect of SU derivates on the risk of malignancy [39]. This was confirmed by Monami et al. with the exception of gliclazide, which appeared to be protective [44]. On the other hand, recently Thakkar et al. revealed increased cancer risk among SU users [40].

Current evidence from observational studies indicate harmful effect of insulin on the cancer risk [18, 37]. In our study insulin use was associated with a dosedependent elevated risk of malignancy. Similar relationship was also observed by Holden et al. [45]. Regarding duration of insulin treatment, risk of malignancy in our 
observation was highest in the first 10 years of treatment, and become insignificant with a longer insulin use. This phenomenon can be explained by increased cancer and also coronary heart disease mortality observed among diabetic patients treated with insulin [46]. Other studies showed increased risk of malignancy associated with insulin use after 4 years of insulin treatment [18]. In general, insulin is a potent growth stimulating hormone acting through insulin and IGF-1 (insulin-like growth factor-1) receptors [34, 47, 48]. On the other hand, landmark prospective studies in type 2 diabetes did not confirm elevated risk of malignancy associated with more intensified treatment [49]. Also Outcome Reduction with an Initial Glargine Intervention (ORIGIN) trial did not demonstrated raised cancer risk among insulin users [50]. However, these studies were of limited duration, also relatively low doses of insulin were used in the ORIGIN trial.

The number of patients treated with other antidiabetic medications in our study was small, therefore we were unable to determine their relationship with cancer risk. Acarbose (the $\alpha$-glucosidase inhibitor) is not popular due to its well-known side effects. DPP-4 inhibitors are not reimbursed in Poland and their utilization is low. In our study, after adjustment to all analyzed variables they demonstrated significant association with cancer risk. However, it is worth to notice that only 17 patients were treated with these agents and in this case random effect cannot be excluded. Pioglitazone and SGLT-2 inhibitors are also not reimbursed and, in addition, pioglitazone was not available on market in Poland up to 2014, thus number of patients using these medications is extremely low.

Obesity is a well-recognized risk factor of several types of cancer [51, 52]. Our study confirmed association between obesity and risk of malignancy in diabetic population. Obese patients, especially with severe obesity (BMI $\geq 35 \mathrm{~kg} / \mathrm{m}^{2}$ ), had significantly higher risk of cancer occurrence compared with non-obese subjects. It should be remembered that with cancer development body weight frequently decreases, the fact which may mar analysis of the results. Insulin resistance, hyperinsulinemia, elevated levels of IGF-1, inflammation, increased sex hormones bioavailability and hyperglycemia are considered to be responsible for increased cancer risk in obese individuals [53].

Smoking is known to be associated with elevated risk of several site-specific cancers, especially lung cancer [54]. Interestingly, in our study number of never, former and current smokers was not significantly different in case and control groups, and smoking was not associated with elevated overall cancer risk. However, not surprisingly, number of current and former smokers was significantly higher in patients with lung cancer related to their comparators.
For other analyzed variables, including place of residence, presence of comorbidities and aspirin use relationship with risk of malignancy was not revealed.

The limitations of our study include its retrospective and observational design, and relatively small sample size which has influenced the statistical power of our findings, and has not allowed to demonstrate other possible relationships for which positive trends were observed. Also immortal time, time-window and time-lag biases despite our best efforts cannot be excluded [55]. Another limitation is low number of users of oral drugs other than sulfonylurea derivatives and metformin. In addition, all main cancer risk factors confirmed in the study e.g., insulin use, $\mathrm{HbA}_{1 \mathrm{c}}$ level and obesity heavily influence one another which may also confound the results. And finally, due to the characteristics of Polish society, only patients of Caucasian ethnicity were included and our findings may have not be applicable for persons from other ethnic groups.

This study has also several strengths. One of them is its case-control design with strictly matched pairs of case subjects and their comparators, with each pair taken from the very same center. The study was based on a high-quality data sources using samples with a long follow-up time (mean time from diabetes diagnosis to index time has exceeded 10 years) and extensive covariate information, including the date of the onset of diabetes, date of cancer diagnosis, treatment details, metabolic control and other common risk factors, which allowed to explore the relationship between T2DM and cancer risk.

\section{Conclusions}

The elderly obese patients with long-standing and poorly controlled type 2 diabetes treated with high doses of insulin are at high risk of cancer development and they should be rigorously assessed towards malignancies, particularly breast cancer in women and colorectal cancer in men.

The results of our study indicate also that metformin therapy should be implemented in all patients without contraindications and without intolerance to this drug. Insulin in type 2 diabetic patients should be introduced with caution and, if possible, high doses of insulin should be avoided. In addition, strong oncological vigilance should be maintained during the first 10 years of insulin treatment. On the other hand, also deterioration of metabolic control should be avoided and increase of $\mathrm{HbA}_{1 \mathrm{c}}$ level above the threshold of $8.5 \%$ should not be allowed.

Finally, our study indicated the important role of weight management in patients with type 2 diabetes. Thus, it is strongly reasonable to strive for weight reduction in obese diabetic patients to reduce risk of obesityrelated complications, including malignancy. 


\section{Abbreviations}

AGEs: Advanced glycation end products; AMPK: AMP-activated protein kinase; BMI: Body mass index; Cl: Confidence interval; DPP-4: Dipeptidylpeptidase-4; HbA, : Hemoglobin $A_{1}$; IGF-1: Insulin-like growth factor-1; LKB1: Liver kinase B1; mTOR: mammalian target of rapamycin; OR: Odds ratio; RAGE: Receptor for AGE; ROS: Reactive oxygen species; SGLT-2: Sodiumglucose transporter; SU: Sulfonylurea; T2DM: Type 2 diabetes mellitus

\section{Acknowledgements}

Not applicable.

\section{Funding}

The work was not granted.

\section{Availability of data and materials}

The datasets generated and analyzed during the current study are available in the University of Rzeszow Repository (http://repozytorium.ur.edu.pl) as an Excel file under the name of the first and also other authors, and the title of our manuscript.

\section{Authors' contributions}

$\mathrm{MD}$ is responsible for the conception and design of the study. MD, ES-G, ZM and TD are responsible for acquisition of data. MD is responsible for statistical analysis. $M D$ and $L C$ are responsible for analysis and interpretation of data, and for manuscript drafting. MD, ES-G, ZM, TD and LC are responsible for critical revision of the work for important intellectual content. All authors read and approved the final manuscript.

\section{Authors' information}

MD - 1. University of Rzeszów, Faculty of Medicine, Institute of Nursing and Health Sciences, Head of Department of Clinical Nutrition; and also 2. diabetic outpatient clinic (secondary level), Rzeszów, Poland. ES-G - Medical University in Łódź, currently Department of Infectious and Liver Diseases, previously Department of Internal Diseases and Diabetology, also diabetic outpatient clinic (tertiary level), Łódź, Poland.

ZM - Private clinic of internal diseases and diabetes, Przemyśl, Poland. TD - Primary care practice, Gniewkowo, Poland.

LC - currently Warsaw Medical University, Head of the Department of Internal Diseases and Diabetology, Warsaw, Poland; previously Medical University in Łódź, Department of Internal Diseases and Diabetology, also diabetic outpatient clinic (tertiary level), Łódź, Poland.

\section{Competing interest}

The authors declare that they have no competing interests.

\section{Consent for publication}

Not applicable.

\section{Ethics approval and consent to participate}

The study was approved by Bioethics Committee at the University of Rzeszow on 19th March 2014, Resolution number 13/03/2014. In accordance with Polish national regulations stated in The Act on Professions of Physician and Dentist of 5th December 1996 (OJ 1997 No. 28, item. 152, as amended) and The Act on Pharmaceutical Law of 6th September 2001 (OJ 2001 No. 126, item. 1381, as amended), in non-interventional, epidemiological studies informed consent is deemed unnecessary.

\section{Author details}

${ }^{1}$ Faculty of Medicine, Institute of Nursing and Health Sciences, University of Rzeszow, Al. Mjr. W. Kopisto 2a, 35-310 Rzeszów, Poland. ²Department of Infectious and Liver Diseases, Medical University of Łódź, ul. Kniaziewicza 1/5, 91-347 Łódź, Poland. ${ }^{3}$ Private Clinic of Internal Diseases and Diabetes, ul. 3 Maja 18, 37-700 Przemyśl, Poland. ${ }^{4}$ NZOZ Esculap, ul. Dworcowa 8, 88-140 Gniewkowo, Poland. ${ }^{5}$ Department of Internal Diseases and Diabetology, Warsaw Medical University, ul. S. Banacha 1a, 02-097 Warsaw, Poland. ${ }^{6} \mathrm{NZOZ}$ "Beta-Med", Plac Wolności 17, 35-073 Rzeszow, Poland.

\section{References}

1. Greenwood M, Wood F. The relation between the cancer and diabetes death rates. J Hyg (Lond). 1914;14:83-118.

2. Rohdenburg GL, Bernhard A, Krehbiel O. Sugar tolerance in cancer. J Am Med Assoc. 1919;72:1528-30.

3. Wang $P$, Kang D, Cao W, Wang Y, Liu Z. Diabetes mellitus and risk of hepatocellular carcinoma: a systematic review and meta-analysis. Diabetes Metab Res Rev. 2012;28:109-22.

4. Ben $Q, X u M$, Ning $X$, et al. Diabetes mellitus and risk of pancreatic cancer: a meta-analysis of cohort studies. Eur J Cancer. 2011;47:1928-37.

5. Sun L, Yu S. Diabetes mellitus is an independent risk factor for colorectal cancer. Dig Dis Sci. 2012;57:1586-97.

6. Tian T, Zhang LQ, Ma XH, Zhou JN, Shen J. Diabetes mellitus and incidence and mortality of gastric cancer: a meta-analysis. Exp Clin Endocrinol Diabetes. 2012:120:217-23.

7. Bao C, Yang X, Xu W, et al. Diabetes mellitus and incidence and mortality of kidney cancer: a meta-analysis. J Diabetes Compl. 2013;27:357-64.

8. Yang X-Q, Xu C, Sun Y, Han R-F. Diabetes mellitus increases the risk of bladder cancer: an updated meta-analysis. Asian Pacific J Cancer Prev. 2013;14:2583-9.

9. Zhang ZH, Su PY, Hao JH, Sun YH. The role of preexisting diabetes mellitus on incidence and mortality of endometrial cancer: a meta-analysis of prospective cohort studies. Int J Gynecol Cancer. 2013;23:294-303.

10. Boyle $\mathrm{P}$, Boniol $\mathrm{M}$, Koechlin $\mathrm{A}$, et al. Diabetes and breast cancer risk: a meta-analysis. Br J Cancer. 2012;107:1608-17.

11. Castillo JJ, Mull N, Reagan JL, Nemr S, Mitri J. Increased incidence of nonHodgkin lymphoma, leukemia, and myeloma in patients with diabetes mellitus type 2: a meta-analysis of observational studies. Blood. 2012;119:4845-50.

12. Turati F, Negri E, La Vecchia C. Family history and the risk of cancer: genetic factors influencing multiple cancer sites. Expert Rev Anticancer Ther. 2014;14:1-4.

13. Espina C, Straif K, Friis S, et al. European code against cancer 4th edition: environment, occupation and cancer. Cancer Epidemiol. 2015:39 Suppl 1:S84-92.

14. Dąbrowski M. Cukrzyca a nowotwory (Diabetes and cancer). Diabet Prakt. 2010;11:54-63 (in Polish).

15. Giovanucci E, Harlan DM, Archer MC, et al. Diabetes and cancer: a consensus report. Diabetes Care. 2010;33:1674-85.

16. Handelsman Y, LeRoith D, Bloomgarden ZT, et al. Diabetes and cancer - an AACE/ACE consensus statement. Diabetes Cancer Endocr Pract. 2013;19:675-93.

17. Franciosi M, Lucisano G, Lapice E, Strippoli GF, Pellegrini F, Nicolucci A. Metformin therapy and risk of cancer in patients with type 2 diabetes: systematic review. PLoS One. 2013;8(8), e71583. doi:10.1371/journal.pone.0071583.

18. Janghorbani M, Dehghani M, Salehi-Marzijarani M. Systematic review and metaanalysis of insulin therapy and risk of cancer. Horm Cancer. 2012:3:137-46.

19. Lutz SZ, Staiger H, Fritsche A, Häring HU. Antihyperglycaemic therapies and cancer risk. Diab Vasc Dis Res. 2014:11:371-89.

20. Centers for Disease Control and Prevention. NHIS - Adult Tobacco Use Information. Available at: http://www.cdc.gov/nchs/nhis/tobacco/tobacco glossary.htm. Accessed 30 June 2015.

21. Wojciechowska U, Didkowska J. Morbidity and mortality of cancer in Poland. The National Cancer Registry, Cancer Centre - Institute for them. Maria Sklodowska - Curie. Available at http://onkologia.org.pl/k/epidemiologia/ Accessed 25 June 2016.

22. Bansal D, Bhansali A, Kapil G, Undela K, Tiwari P. Type 2 diabetes and risk of prostate cancer: a meta-analysis of observational studies. Prostate Cancer Prostatic Dis. 2013;16:151-8.

23. Yang $X$, Ko GTC, So WY, et al. Associations of hyperglycemia and insulin usage with the risk of cancer in type 2 diabetes: the Hong Kong diabetes registry. Diabetes. 2010;59:1254-60.

24. Donadon V, Balbi M, Valent F, Avogaro A. Glycated hemoglobin and antidiabetic strategies as risk factors for hepatocellular carcinoma. World J Gastroenterol. 2010;16(24):3025-32.

25. Dabrowski M. Glycated hemoglobin, diabetes treatment and cancer risk in type 2 diabetes. A case-control study. Ann Agricult Environment Med. 2013:20:116-21.

26. Travier N, Jeffreys M, Brewer N, et al. Association between glycosylated hemoglobin and cancer risk: a New Zealand linkage study. Ann Oncol. 2007:18:1414-9. 
27. Joshu CE, Prizment AE, Dluzniewski PJ, et al. Glycated hemoglobin and cancer incidence and mortality in the Atherosclerosis in Communities (ARIC) study, 1990-2006. Int J Cancer. 2012;131:1667-77.

28. Siddiqui AA, Spechler SJ, Huerta S, Dredar S, Little BB, Cryer B. Elevated $\mathrm{HbA}_{1 \mathrm{c}}$ is an independent predictor of aggressive clinical behavior in patients with colorectal cancer: a case-control study. Dig Dis Sci. 2008;53:2486-94.

29. Miao Jonasson J, Cederholm J, Eliasson B, Zethelius B, Eeg-Olofsson K, Gudbjörnsdottir S. HbA1c and cancer risk in patients with type 2 diabetes a nationwide population-based prospective cohort study in Sweden. PLoS One. 2012;7(6), e38784.

30. de Beer JC, Liebenberg L. Does cancer risk increase with $\mathrm{HbA}_{1 \mathrm{c}}$ independent of diabetes? British J Cancer. 2014;110:2361-8.

31. Abe R, Yamagishi S. AGE-RAGE system and carcinogenesis. Curr Pharm Des. 2008;14:940-5.

32. Riehl A, Németh J, Angel P, Hess J. The receptor RAGE: bridging inflammation and cancer. Cell Commun Signal. 2009;7:12

33. Ryu TY, Park J, Scherer PE. Hyperglycemia as a risk factor for cancer progression. Diabetes Metab J. 2014;38:330-6.

34. Heuson JC, Legros N, Heimann R. Influence of insulin administration on growth of the 7,12-dimethylbenz(a)anthracene-induced mammary carcinoma in intact, oophorectomized, and hypophysectomized rats. Cancer Res. 1972;32:233-8.

35. Johnson JA, Bowker SL, Richardson K, Marra CA. Time-varying incidence of cancer after the onset of type 2 diabetes: evidence of potential detection bias. Diabetologia. 2011;54:2263-71.

36. Carstensen B, Witte DR, Friis S. Cancer occurrence in Danish diabetic patients: duration and insulin effects. Diabetologia. 2012;55:948-58.

37. Li C, Zhao G, Okoro CA, Wen XJ, Ford ES, Balluz LS. Prevalence of diagnosed cancer according to duration of diagnosed diabetes and current insulin use among U.S. adults with diagnosed diabetes: findings from the 2009 Behavioral Risk Factor Surveillance System. Diabetes Care. 2013;36:1569-76.

38. Dąbrowski M, Grondecka A. Diabetes is a risk factor of hospitalization in the surgical ward due to the cancer in elderly and middle-aged population. Arch Med Sci 2016, DOl: 10.5114/aoms.2016.58666, Published online 22 Mar 2016

39. Soranna D, Scotti L, Zambon A, et al. Cancer risk associated with use of metformin and sulfonylurea in type 2 diabetes: a meta-analysis. Oncologist. 2012;17:813-22.

40. Thakkar B, Aronis KN, Vamvini MT, Shields K, Mantzoros CS. Metformin and sulfonylureas in relation to cancer risk in type II diabetes patients: a metaanalysis using primary data of published studies. Metabolism. 2013;62:922-34.

41. Kowall B, Stang A, Rathmann W, Kostev K. No reduced risk of overall, colorectal, lung, breast, and prostate cancer with metformin therapy in diabetic patients: database analyses from Germany and the UK. Pharmacoepidemiol Drug Saf. 2015;24:865-74.

42. Aljada A, Mousa SA. Metformin and neoplasia: implications and indications. Pharmacol Ther. 2012;133:108-15.

43. Eikawa S, Nishida M, Mizukami S, Yamazaki C, Nakayama E, Udono H. Immune-mediated antitumor effect by type 2 diabetes drug, metformin Proc Natl Acad Sci U S A. 2015;112:1809-14.

44. Monami M, Lamanna C, Balzi D, Marchionni N, Mannucci E. Sulphonylureas and cancer: a case-control study. Acta Diabetol. 2009;46:279-84.

45. Holden SE, Jenkins-Jones S, Morgan CL, Schernthaner G, Currie CJ. Glucoselowering with exogenous insulin monotherapy in type 2 diabetes: dose association with all-cause mortality, cardiovascular events and cancer. Diabetes Obes Metab. 2015;17:350-62.

46. Forssas E, Sund R, Manderbacka K, Arffman M, llanne-Parikka P, Keskimäki I. Increased cancer mortality in diabetic people treated with insulin: a registerbased follow-up study. BMC Health Serv Res. 2013;13:267.

47. Belfiore A, Malaguarnera R. Insulin receptor and cancer. Endocr Relat Cancer. 2011;18:R125-47.

48. Vigneri P, Frasca F, Sciacca L, Pandini G, Vigneri R. Diabetes and cancer. Endocr Relat Cancer. 2009;16:1103-23.

49. Gerstein HC. Does insulin therapy promote, reduce, or have a neutral effect on cancers? JAMA. 2010;303:446-7.

50. The ORIGIN Trial Investigators, Gerstein HC, Bosch J, Dagenais GR, et al. Basal insulin and cardiovascular and other outcomes in dysglycemia. N Engl J Med. 2012;367:319-28.

51. Renehan AG, Tyson M, Egger M, Heller RF, Zwahlen M. Body-mass index and incidence of cancer: a systematic review and meta-analysis of prospective observational studies. Lancet. 2008;371:569-78.
52. Wolin KY, Carson K, Colditz GA. Obesity and cancer. Oncologist. 2010;15:556-65.

53. Garg SK, Maurer H, Reed K, Selagamsetty R. Diabetes and cancer: two diseases with obesity as a common risk factor. Diabetes Obes Metab. 2014;16:97-110.

54. Gandini S, Botteri E, lodice $\mathrm{S}$, et al. Tobacco smoking and cancer: a meta-analysis. Int J Cancer. 2008;122:155-64.

55. Suissa S, Azoulay L. Metformin and the risk of cancer. Time-related biases in observational studies. Diabetes Care. 2012;35:2665-73.

\section{Submit your next manuscript to BioMed Central and we will help you at every step:}

- We accept pre-submission inquiries

- Our selector tool helps you to find the most relevant journal

- We provide round the clock customer support

- Convenient online submission

- Thorough peer review

- Inclusion in PubMed and all major indexing services

- Maximum visibility for your research

Submit your manuscript at www.biomedcentral.com/submit
C Biomed Central 